\title{
Oral Hygiene and Gingival Health in Patients with Fixed Prosthodontic Appliances - A Six Month Follow-up
}

\section{KC Basnyat S, Sapkota B, Shrestha S}

Department of Prosthodontics

Kathmandu University School of Medical Sciences

Dhulikhel, Kavre, Nepal.

\section{Corresponding Author}

Smriti KC Basnyat

Department of Prosthodontics

Kathmandu University School of Medical Sciences

Dhulikhel, Kavre, Nepal.

E-mail: smritikc5@gmail.com

\section{Citation}

KC Basnyat S, Sapkota B, Shrestha S. Oral Hygiene and Gingival Health in Patients with Fixed Prosthodontic Appliances-A Six Month Follow-Up. Kathmandu Univ Med J 2015;52(4):328-32.

\section{ABSTRACT}

\section{Background}

Gingival inflammation and periodontal disease are the common complications of fixed dental prosthesis. They can be overcome by good oral hygiene maintenance.

\section{Objective}

The objective of this study was to assess the oral hygiene and gingival condition in patients after placement of fixed dental prosthesis for a period of six months. It was also analyzed how factors like type of fixed dental prosthesis (Single crown, fixed partial denture) and material (Metal, Porcelain fused to metal) are statistically associated with oral hygiene and gingival health.

\section{Method}

The sample consisted of 50 patients visiting the Dental Outpatient Department of Dhulikhel Hospital. The oral examinations were conducted using basic diagnostic tools (Mouth mirror, periodontal probe and explorer). Teeth and gingiva were examined using the Plaque and Gingiva Index by Silness and Löe. The examinations were conducted after 14 days and six months after placement of fixed dental prosthesis along with the oral hygiene instructions. Paired sample t-test were done to find statistical association using SPSS 16.0.

\section{Result}

Our results revealed no significant difference in plaque index among patients with single crown whereas fixed partial denture showed statistical significance. No significant differences were found for type of material. The statistical analysis showed similar results for gingival index.

\section{Conclusion}

Our research showed that single crown had no significant difference on Plaque index and Gingival index of the patient after 14 days and six months, whereas, Fixed partial denture showed significant difference. Both metal and porcelain fused to metal crown revealed no statistically significant difference on Plaque index and Gingival index.

\section{KEY WORDS}

Fixed partial denture, gingival index, oral hygiene, plaque index, single crown 


\section{INTRODUCTION}

The fixed dental prosthesis is one of the most commonly used prosthesis in dental clinical practice for restoring function and health of oral tissues. The single crown and fixed partial denture (FPD) are the two major type of fixed dental prosthesis. The dental prosthesis are made up of different materials and the generally used materials are metal, porcelain fused to metal and ceramic.

The success of fixed dental prosthesis depends on many factors which should be considered during treatment planning. Tooth decay, gingival inflammation and periodontal disease are quoted as the most common biological complications of fixed dental prosthesis. ${ }^{1-6} \mathrm{Among}$ this, tooth decay is the most frequent reason of failure. ${ }^{7,8} \mathrm{It}$ is well known that these conditions are caused by bacteria settled in the dentogingival plaque accumulated due to insufficient oral hygiene, and consequently, for oral health the appropriate hygiene regime is crucial. ${ }^{9}$ The relationship between bacterial plaque accumulation and gingival inflammation has been well documented. ${ }^{10}$ Patient's susceptibility to gingival inflammation is not based solely on the quantity of dental plaque, but also some contributing factors, for example, ill-fitting, overhanging crowns etc.

The aim of this study was to assess and observe oral hygiene and gingival condition through a six month period in patients who received instructions in oral hygiene after fixed prosthodontic treatment. It was also analyzed how factors such as a type of fixed dental prosthesis, constructive material influenced the oral hygiene and gingival health of the patient.

\section{METHODS}

Required data oral hygiene was acquired from the subjects and the observation data were filled personally. Therefore the data were only primary and no secondary data were included. Patients visiting the Dental Outpatient Department (DOPD) of Dhulikhel Hospital, Kathmandu University were selected for the study. The total numbers of patients involved in the study were 50 and the duration of study was 6 months (June 2014 to December 2014).

The inclusion criteria were: adult who were systemically healthy, non-pregnant, non-smokers. Patients were excluded from the study if there were evidence of generalized periodontal problems, medical history which may affect the periodontal status such as Diabetes, Hepatitis, HIV, habit of eating pan, supari, patients on drugs which cause hyperplasia of gums such as Contraceptive pill, Cyclosporine A, Phenobarbital and transplant patients because their immunity may be impaired. Patient of age group below 18, patients having both crown and fixed partial denture, no correct gingival-adjacent restorations, overhang, unsuitable contour, lack of restoration margin fit were excluded. Informed consents were obtained from the enrolled subjects after explaining the nature of the study and possible risks and discomfort.

The examination was conducted using basic diagnostic tools like mouth mirror, periodontal probe, and explorer. During examination, the entire sulcus of the abutment tooth was probed, and readings were taken at six points. Plague index and gingival index were calculated 14 days and six months after the placement of prosthesis on abutment teeth.

Plaque and Gingival index were recorded as given below:

\section{Plaque Index (PI):}

Plaque identification was done using an Erythosine disclosing solution based on Silness \& Loe, ${ }^{11}$ six surfaces of the tooth were measured (mesio-buccal, buccal, distobuccal, disto-lingual, lingual and mesial-lingual) were given a score from 0 to 3 . The scores from the six areas of the tooth were added and divided by six in order to give the plaque index for the tooth with the following scores and criteria:

0- no plaque;

1- A film of plaque adhering to the free gingival margin and adjacent area of the tooth.The plaque may be insitu only after the application of disclosing solution or by using the probe on the tooth surface;

2- Moderate accumulation of soft deposit within gingival pocket or the tooth and gingival margin which can be seen with the naked eye;

3- Abundance of soft matter within the gingival pocket and or on the tooth and gingival margin. ${ }^{11}$

\section{Gingival index (GI):}

Tooth were examined for gingival inflammation signs and recorded based on Silness \& Loe. ${ }^{11}$ The score was given as follows:

0- Healthy;

1- Mild inflammatory, slight changes in colour, with little change in texture;

2- Moderate inflammation, moderate glazing, redness, oedema and hypertrophy. Bleeding on pressure at entire sulcus;

3- Severe inflammation, marked redness and hypertrophy tendency to spontaneous bleeding ulceration.

Average score of six surfaces of the teeth (mesio-buccal, buccal, disto-buccal, disto-lingual, lingual and mesiallingual) of specific tooth were taken and were divided by six. ${ }^{12}$

After the placement of the single crown or fixed partial denture the patient were instructed about oral hygiene maintenance and demonstrations were given on models about how to use the interdental brushes and floss.

The collected data were analyzed using the statistical 
package for social sciences (SPSS 16.0). The statistical differences in the clinical parameters (PI and GI) at 14 days and six months follow up were accessed, for type of fixed dental prosthesis and type of material, using the paired sample t-test. The level of significance was set at $p$-value $<0.05$.

The research involved no sources of fund either from Kathmandu university Dhulikhel hospital or other external sources.

\section{RESULTS}

Total 50 patients were examined during the research work. The demographic characteristics are given in Table 1. Of the total patients, 27 patients fell under the age group $18-40$ years, 19 were $41-60$ years old and the remaining four above 60 years of age. Coincidentally there were as many female patients as there were males. Out of total 50 patients who underwent prosthodontic treatment, 32 had single crown and 18 had fixed partial denture. As regarding the type of material used for prosthesis 20 had metal crown and 30 had porcelain fused to metal crown. The statistical data like mean, standard deviation, stand error of mean etc are presented in Table 2 and Table 3.

Table 1. Demographic characteristics.

\begin{tabular}{|c|c|c|}
\hline Variable & Frequency $(n=50)$ & (\%) \\
\hline \multicolumn{3}{|l|}{ Age } \\
\hline $18-40$ years & 27 & 54 \\
\hline $41-60$ years & 19 & 38 \\
\hline$>60$ years & 4 & 8 \\
\hline \multicolumn{3}{|l|}{ Gender } \\
\hline Male & 25 & 50 \\
\hline Female & 25 & 50 \\
\hline \multicolumn{3}{|c|}{ Type of fixed dental prosthesis } \\
\hline Single crown & 32 & 64 \\
\hline Fixed partial denture & 18 & 36 \\
\hline \multicolumn{3}{|l|}{ Type of material } \\
\hline Metal & 20 & 40 \\
\hline Porcelain fused to metal & 30 & 60 \\
\hline
\end{tabular}

\section{Plaque index}

Results of descriptive statistics regarding plaque index were presented in Table 2 and 3. The difference of plaque index after 14 days and six months of placement of Single crown was not statistically significant $(p=0.378)$. The difference of plaque index after 14 days and six months of placement of FPD were statistically significant $(p=0.006)$.

Paired sample t-test for the plaque index, after 14 days and six months follow up, on dental prosthesis made of metal were not significantly different $(p=0.062)$.

Paired sample t-test for the plaque index, after 14 days and six months follow up, on dental prosthesis made of Porcelian fused to metal were not significantly different $(p=0.077)$.
Table 2. Mean values of clinical parameters and type of fixed dental prosthesis

\begin{tabular}{|c|c|c|c|c|c|c|}
\hline \multirow{2}{*}{$\begin{array}{l}\text { Type } \\
\text { of } \\
\text { FDP }\end{array}$} & \multirow{2}{*}{$\begin{array}{l}\text { Clinical parameters } \\
\text { (Plaque index / } \\
\text { Gingival index) }\end{array}$} & \multicolumn{3}{|c|}{$\begin{array}{c}\text { Paired } \\
\text { Differences }\end{array}$} & \multirow[t]{2}{*}{$t$} & \multirow[t]{2}{*}{$\begin{array}{c}\mathrm{p}- \\
\text { value }\end{array}$} \\
\hline & & Mean & $\begin{array}{l}\text { Std. } \\
\text { Devia- } \\
\text { tion }\end{array}$ & $\begin{array}{l}\text { Std. } \\
\text { Error } \\
\text { Mean }\end{array}$ & & \\
\hline \multirow{2}{*}{$\begin{array}{l}\text { Single } \\
\text { Crown }\end{array}$} & $\begin{array}{l}\text { PI } 14 \text { days-PI six- } \\
\text { months }\end{array}$ & 0.052 & 0.374 & 0.083 & 2.446 & 0.062 \\
\hline & $\begin{array}{l}\text { GI } 14 \text { days-GI six- } \\
\text { months }\end{array}$ & 0.043 & 0.204 & 0.457 & 2.108 & 0.061 \\
\hline \multirow{2}{*}{ FPD } & $\begin{array}{l}\text { PI } 14 \text { days-PI } \\
\text { sixmonths }\end{array}$ & 0.206 & 0.343 & 0.062 & 1.835 & 0.077 \\
\hline & $\begin{array}{l}\text { GI } 14 \text { days-GI six- } \\
\text { months }\end{array}$ & 0.096 & 0.267 & 0.048 & 1.339 & 0.191 \\
\hline
\end{tabular}

Paired sample t-test; $p<0.05$ significant, $p>0.05$ not significant

Table 3. Mean values of clinical parameters and type of material of fixed dental prosthesis.

\begin{tabular}{|c|c|c|c|c|c|c|}
\hline \multirow{2}{*}{$\begin{array}{l}\text { Type of } \\
\text { material } \\
\text { of FDP }\end{array}$} & \multirow{2}{*}{$\begin{array}{l}\text { Clinical param- } \\
\text { eters (Plaque } \\
\text { index /Gingival } \\
\text { index) }\end{array}$} & \multicolumn{3}{|c|}{$\begin{array}{c}\text { Paired } \\
\text { Differences }\end{array}$} & \multirow[t]{2}{*}{$t$} & \multirow[t]{2}{*}{$\begin{array}{c}\mathrm{p}- \\
\text { value }\end{array}$} \\
\hline & & Mean & $\begin{array}{l}\text { Std. } \\
\text { Devia- } \\
\text { tion }\end{array}$ & $\begin{array}{l}\text { Std. } \\
\text { Error } \\
\text { Mean }\end{array}$ & & \\
\hline \multirow{3}{*}{ Metal } & $\begin{array}{l}\text { PI } 14 \text { days-PI six } \\
\text { months }\end{array}$ & 0.205 & 0.247 & 0.058 & 0.904 & 0.378 \\
\hline & & & & & & \\
\hline & $\begin{array}{l}\text { GI } 14 \text { days-GI six- } \\
\text { months }\end{array}$ & 0.096 & 0.304 & 0.071 & 0.611 & 0.549 \\
\hline \multirow{2}{*}{$\begin{array}{l}\text { Por- } \\
\text { celian } \\
\text { fused to } \\
\text { metal }\end{array}$} & $\begin{array}{l}\mathrm{PI} 14 \text { days-PI six } \\
\text { months }\end{array}$ & 0.115 & 0.396 & 0.070 & 2.943 & 0.006 \\
\hline & $\begin{array}{l}\text { GI } 14 \text { days-GI six- } \\
\text { months }\end{array}$ & 0.065 & 0.202 & 0.035 & 2.709 & 0.011 \\
\hline
\end{tabular}

Paired sample t-test; $p<0.05$ significant, $p>0.05$ not significant

\section{Gingival index}

Results of descriptive statistics regarding gingival index were shown in Table 2 and 3. The difference of plaque index after 14 days and 6 months of placement of Single crown were not statistically significant $(p=0.378)$. The difference of Gingival index after 14 days and six months of placement of FPD were statistically significant $(p=0.011)$.

Paired sample t-test for the Gingival index, after 14 days and six months follow up, on dental prosthesis made of metal were not significantly different $(p=0.061)$.

Paired sample t-test for the gingival index, after 14 days and six months follow up, on dental prosthesis made of porcelain fused to metal were not significantly different $(p=0.191)$.

\section{DISCUSSION}

There are many studies on this topic indicating that dental prosthesis favour plaque accumulation and have a negative impact on gingival condition due to insufficient aftercare. ${ }^{13}$ 
In this study, the frequency of plaque found during the preliminary visit was higher than that found after six months, of prosthodontic treatment. The most of patients presented with the plaque index value of 0 and 1 during the reexaminations, thus indicating that they maintained a satisfactory level of oral hygiene. This could be contributed to the reexamination and reinstruction scheme. Reinstruction is detected as an important factor, since patients in other investigations show lower plaque scores after reinstruction. ${ }^{14}$ It is concluded that professional advice and instruction and reinstruction seems very important in order to obtain good plaque control. ${ }^{14}$ In our study the oral hygiene instructions were given directly after crown or FPD. Patients were reinstructed and reminded of the importance of oral hygiene after 14 days, and six months.

The study by Lorato DC indicated that plaque accumulation, and consequently the incidence of tooth decay were higher in fixed partial denture compared to single crowns. ${ }^{15}$ One of the reasons could be the occasionally difficult to access for dental hygiene instruments into the inter proximal areas and beneath the pontics of FPD. ${ }^{16}$ The above findings were in accordance to our study which shows no statistically significant difference for plaque index between 14 days and six months after placement of single crown $(p=0.378)$, whereas, FPD were significantly different $(p=0.006)$. The 14 days and six months follow up indicated no statistically significant difference on gingival index for single crown $(p=0.549)$, whereas, FPD were statistically significant $(p=0.011)$. A study reported a lower percentage of gingivitis around the crowns after two years when compared to baseline conditions. ${ }^{17}$

Some studies have shown that factors such as open and over-hanging margins, irregular surface texture and over contoured morphology contribute to poor gingival health around crowns. ${ }^{18}$ The above finding is in contradiction to our study because the factors considered in the above study were taken as the exclusion criteria in our study.

Fixed dental prosthesis may be made of different materials. Our patients usually opt for either metal crown, porcelain fused to metal or all ceramic. Our examination revealed that plaque index, after 14 days and six months follow up, on dental prosthesis made of metal were not significantly different $(p=0.062)$ and similarly for Porcelain fused to metal were not significantly different $(p=0.077)$ as well. The gingival index, after 14 days and six months follow up, on dental prosthesis made of metal were not significantly different $(p=0.061)$ and similarly porcelain fused to metal were not significantly different $(p=0.191)$ as well.

\section{REFERENCES}

1. Brägger U, Aeschlimann S, Bürgin W, Hämmerle CH, Lang NP. Biological and technical complications and failures with fixed partial dentures (FPD) on implants and teeth after four to five years of function. Clin Oral Implants Res, 2001;12(1):26-34
Reitemeier reported that type of alloy did not affect the level of plaque accumulation and gingival health were similar around any alloy. ${ }^{19}$ Christensen in a comparison of zirconium to metal fused to porcelain crowns also made similar conclusions. ${ }^{20}$ Kancyper also noted similar findings. ${ }^{21}$ This is in accordance to other clinical studies which demonstrate that the amount of plaque on the test specimens of different dental materials shows no consistent differences. ${ }^{22}$ The results of our study were in agreement with above mentioned studies. Our samples were comparably matched for the porcelain fused to metal and metal crowns and presented an equal chance to both types of materials for a good comparison. It may however be noted that these observations are contradicted by some researchers. Al-Wahadni reported that all ceramic restorations attract more plaque irrespective of level of placement. ${ }^{23}$ which in our study falls under exclusion criteria. Gemalmaz in a clinical trial of IPS Empress Crowns also agreed with Al-Wahadni. ${ }^{24}$ Weishaupt et al. concluded in their study that galvanoceramic crowns may accumulate less plaque as compared to metal ceramic crowns. They attributed certain stabilizing effect of this particular material for a favorable gingival response. ${ }^{25}$

The period of monitoring in this study was too short to make reliable conclusions as other studies show that length of use of crowns influenced significantly the level of oral hygiene and gingival reaction. ${ }^{26}$ Due to time constraint, only 50 patients could be considered for the study. Therefore future research should include more number of samples so that the statistical analysis gives more reliable result, and more pertinently in this case the study period should be five years or above which is considered more critical for FPD. The research will help the patients by increasing their awareness about oral hygiene and maintenance.

\section{CONCLUSION}

Our research showed that in type of fixed dental prosthesis used, single crown had no significant difference on PI and GI of the patient after 14 days and six months after placement of crown, whereas, FPD showed significant difference. Among the type of material used in fixed dental prosthesis, both metal and porcelain fused to metal crown revealed no statistically significant difference on $\mathrm{PI}$ and $\mathrm{GI}$.

\section{ACKNOWLEDGEMENT}

I would like to acknowledge Dr. Manoj Humagain, Dr. Poshan Dahal, Dr. Mamta Shakya for their help during collection of data.
2. Hämmerle $\mathrm{CH}$, Ungerer $\mathrm{MC}$, Fantoni $P C$, Brägger $U$, Bürgin $W$, Lang NP. Long-term analysis of biologic and technical aspects of fixed partial dentures with cantilevers. Int J Prosthodont 2000;13(5):409-15. 
3. Karlsson S.Failures and length of service in fixed prosthodontics after long-term function. A longitudinal clinical study. Swed Dent J. 1989;13(5):185-92

4. Leempoel PJ, Eschen S, De Haan AF, Van't Hof MA. An evaluation of crowns and bridges in a general dental practice. J Oral Rehabil $1985 ; 12(6): 515-28$

5. Valderhaug J. A 15-year clinical evaluation of fixed prosthodontics. Acta Odontol Scand $1991 ; 49(1): 35-40$.

6. Valderhaug J. Periodontal conditions and carious lesions following the insertion of fixed prostheses: a 10-year follow-up study. Int. Dent. J. $1980 ; 30(4): 296-304$.

7. Glantz PO, Nilner K, Jendresen MD, Sundberg H. Quality of fixed prosthodontics after 15 years. Acta Odon- tol Scand. 1993 ;51(4): 247-52.

8. Karlsson S. A clinical evaluation of fixed bridges, 10 years following insertion. J Oral Rehabil. 1986;13(5):423-32.

9. Lang NP, Attstrom R, Loe H. Proceedings of the European workshop on mechanical plaque control. Quintessence, Berlin, 1998;287-299.

10. Bjorn A, Bjorn H, Grkovic B. Marginal fit of restorations and its relation to periodontal bone level. II. Crowns Odontol Revy 1970; 21:337-46.

11. Silness $P$, Loe $H$. Periodontal disease in pregnancy. II. Correlation between oralhygiene and periodontal condition. Acta Odontologica Scandinavica. 1964;24: 747-59.

12. Loe $H$, Silness J. Gingival index, Text book of preventive and community dentistry. Res: 1963:184-185.

13. Jared $\mathrm{H}$, Zhong $\mathrm{Y}$, Rowe M, Ebisutani K, Tanaka T, Takase N. Clinical trial of a novel interdental brush cleaning system. J Clin Dent. $2005 ; 16(2): 47-52$.

14. Roscher T, Rosing CK, Gjermo P, Aass AM. Effect of instruction and motivation in the use of electric an $d$ manual toothbrushes in periodontal patients. A comparative study. Braz Oral Res. 2004; 18:296-300.
15. Lorato DC. Effects of artifical crown margin extension and tooth brushing frequency on gingival pocket depth. J Prosthet Dent. 1975;34(6):640-3.

16. Tolboe H, Isidor F, Budtz-Jörgensen $E$, Kaaber S. Influence of pontic material on alveolar mucosal conditions. Scand J Dent Res. 1988; 96(5):442-7.

17. Milleding P, Haag P, Neroth B, Renz I. Two years of clinical experience with Procera titanium crowns. Int J Prosthodont. 1998;11:224-32.

18. Silness J. Peridontal conditions in patients treated with dental bridges: The relationship between the location of the crown margin and the periodontal condition. J Periodontal Res 1970;5:225-9.

19. Reitemeier B, Hansel K, Walter MH, Kastner C, Toutenburg H. Effect of posterior crown margin placement on gingival health. J Prosthet Dent. 2002;87:167-72

20. Christensen GJ. Porcelain-fused-to-metal versus zirconia-based ceramic restorations, 2009. J Am Dent Assoc. 2009;140:1036-9.

21. Kan cyper SG, Koka S. The influence of intracrevicular crown margins on gingival health: preliminary findings. J Prosthet Dent. 2001 ; 85:461-465.

22. Adamczyk E, Spiechowicz E. Plaque accumulation on crowns made of various materials. Int J Prosthodont. 1990;3:285-91.

23. Al-Wahadni AM, Mansour Y, Khader Y. Periodontal response to allceramic crowns (IPS Empress) in general practice. Int J Dent Hyg. 2006;4:41-6.

24. Gemalmaz D, Ergin S. Clinical evaluation of allceramic crowns. J Prosthet Dent. 2002;87:189-96.

25. Weishaupt $P$, Bernimoulin JP, Lange KP, Rothe $S$, Na umann $M$, Hagewald S. Clinical and inflammatory effects of galvano-ceramic and metal-ceramic crowns on periodontal tissues. J Oral Rehabil. 2007;34:941-947.

26. Jameson LM. Comparison of the volum of crevicular fluid from restored and nonrestored teeth. J Prosthet Dent. 1979 Feb;41(2): 209-14. 